La Junta

REVISTA DE INNOVACIÓN E INVESTIGACIÓN CONTABLE

\title{
Palabras del director
}

Han transcurrido tres años desde la creación de LA JUNTA. Revista de innovación e investigación contable, importante proyecto editorial a cargo de la Junta de Decanos de Colegios de Contadores Públicos del Perú, el cual va consolidando sus objetivos y metas de mediano plazo, con una publicación ininterrumpida, hasta llegar a la sexta edición, primera del año 2021, la cual presentamos con mucha satisfacción. La crisis sanitaria iniciada en el año 2020, la que continúa hasta la fecha de esta publicación, no ha sido impedimento para que los profesionales, docentes e investigadores, realicen proyectos de investigación y los postulen a la revista, para ser sometidos al proceso de evaluación por pares especialistas bajo la modalidad de doble ciego, antes de su aceptación para publicación.

La coyuntura de la crisis sanitaria originada por la Covid-19, así como la adecuación de la enseñanza a la modalidad no presencial, ha sido todo un desafío para las universidades y para las instituciones, como los Colegios de Contadores Públicos, que han tenido que adecuar la educación universitaria y la formación continua profesional, a nuevos formatos y estrategias, para los que la mayoría no estaba capacitado ni preparado. Estos aspectos se ven reflejados en algunas de las investigaciones incluidas en esta edición, con un análisis que lo vincula a la coyuntura y contribuye con la identificación de los factores relacionados a su implementación. Las consecuencias de la actual crisis sanitaria en todos los campos, seguirá siendo materia de análisis y discusión en los próximos años por parte de los profesionales e investigadores, por lo que se espera que La Junta siga ocupando una posición privilegiada entre las revistas científicas, para exponer los resultados de sus proyecto de investigación, sobre todo, aquellos vinculados al quehacer de la disciplina contable. 
Es importante mencionar que se ha procedido a crear una nueva página web para la revista, la cual incorpora los requerimientos internacionales necesarios para este tipo de publicaciones, de tal forma que contribuya con el proceso de indización de la revista, mediante la instalación y personalización del Open Journal Systems (OJS), que es un sistema de administración y publicación de revistas. Esto va acompañado con una reestructuración de las secciones y el acceso a todos los contenidos publicados desde la creación de la revista.

A nombre de los integrantes del Comité Editorial de la revista, les transmito el agradecimiento especial a todos los que contribuyen para que nuestro proyecto editorial, el de todos los Contadores Públicos del país, continúe en forma ininterrumpida. Asimismo, agradecemos a los autores y a los árbitros que han participado en esta primera edición del año 2021, esperamos seguir contando con su aporte y colaboración desinteresada. 